\title{
Long term quality of life after a wildfire disaster in a rural part of Greece*
}

\author{
Vicky Papanikolaou ${ }^{1}$, Dimitrios Adamis ${ }^{2}$, John Kyriopoulos ${ }^{1}$ \\ ${ }^{1}$ Department of Health Service Management, National School of Public Health, Athens, Greece \\ ${ }^{2}$ Research and Academic Institute of Athens, Athens, Greece \\ Email: vpapan@hol.gr, bpapanikolaou@esdy.edu.gr, jkyriopoulos@esdy.edu.gr,dimaadamis@yahoo.com
}

Received 7 February 2012; revised 5 March 2012; accepted 28 March 2012

\begin{abstract}
Purpose: The main aims of this study were to evaluate the quality of life of wildfire victims and compare it with that of a control sample of people unaffected by the disaster, and to identify confounder factors (previous psychiatric caseness, demographic factors and losses) which may influence the quality of life. Methods: This was a cross sectional case-control study. Participants belonged to an adult population which had taken part in a previous study 6 months after the disaster. The measured variables were: 1) quality of life using the WHOQOL-BREF measure, 2) previous psychiatric caseness as identified using the SCL-90-R and 3) demographics. Results: Victims of the wildfires had a statistically significant poorer quality of life in the three domains of physical health, psychological health, and environment compared to controls. After adjusting for other variables, the only difference between victims and controls was in the environment domain. Conclusions: Disasters have long lasting effects on victims. Psychological and physical health may improve after some time but environmental quality of life may need longer. However, it is not known yet if the environmental aspect of quality of life could affect other aspects such as psychological health or social relationships in the future.
\end{abstract}

Keywords: Quality of Life; Disasters; Wildfires; Greece; Adults; WHOQOL-BREF

\section{INTRODUCTION}

The psychosocial aspects of disasters have received increasing attention recently. Although disasters differ widely, they usually have some common long-lasting psychological and social consequences [1]. Psychological symptoms can range from very mild and transient ones,

"Conflict of interest: the authors declare that they have no conflict of interest. such as altered behaviour or acute distress, to severe psychiatric disorders, such as major depression and suicidality [2]. In addition, studies have shown reduced levels of Quality of Life (QoL) in the affected populations [3, 4]. The World Health Organization (WHO) defines QoL as the "individuals' perceptions of their position in life in the context of the culture and value systems in which they live and in relation to their goals, expectations, standards and concerns" [5]. QoL is a broad concept incorporating a person's physical health, psychological state, level of independence, social relationships, personal beliefs and relationships to main features of the environment. QoL has been widely used in social science as a measure of social development and living standard, and is a sensitive and comprehensive index [6]. Moreover, QoL has been used to evaluate the impact of chronic diseases such as cancer, renal diseases or mental illness as well as a measurement of outcomes [7-10]. Previous studies have documented the effects of natural disasters on the shortand long-term health and well-being of individuals. One study [3] assessed quality of life before and after the 1999 Chi-Chi earthquake in elderly individuals. They reported that one year after the earthquake elderly people had a lower quality of life in domains related to physical health, psychological well-being, and environment compared to baseline pre-disaster assessments. Similar results for earthquake disasters were reported by $[11,12]$ and for floods by [13]. In addition, others [14] have reported that high levels of negative post-disaster adjustment were associated with personal injuries, resource loss, and increased psychopathological symptoms. The quality of life in the aftermath of a disaster also depended on the severity of the psychiatric impairment. The more the psychiatric problems are, the lower the quality of life becomes $[12,15,16]$. Thus, there are indications that after a disaster the affected population except of the direct losses from the disaster suffers for longer time from secondary psychosocial problems which may impair the quality of life in the community for quite some time.

In this study we examined the quality of life of those 
affected by a wildfire in a rural area of Greece three years after the disaster. More specifically, the aims of the study were 1) to examine the quality of life of the victims of the wildfires that occurred in 2007 in Greece, 2) to compare the quality of life of those affected by the disaster (cases) with the quality of life of those who were not (controls) and 3) to examine other factors which may have a significant effect on the quality of life (psychological factors, losses, and demographics).

\section{METHODS}

\subsection{History}

In August 2007, an intense and destructive wildfire broke out in the Peloponnesus peninsula in Greece. This was the worst wildfire of the century in Greece. The fires destroyed villages, forests and farmland. Sixty to eighty people were reported killed and 5392 people were affected by the disaster [17]. About 1500 square kilometres of forests, olive trees, farmland, and villages were burned in these fires and the economic damages were estimated at around 1,750,000 $(\times 1000)$ US\$. The government declared a national disaster and the areas affected by the fires were designated for further support.

\subsection{Participants}

From our previous study [18], we followed up residents who lived in the most affected area (that of the prefecture of Ilia). The previous study was a cross-sectional casecontrol study. The cases were randomly selected from residents who lived in the regions characterized as disaster areas by the Hellenic Republic Ministry of Interior. The controls were matched to the cases in terms of gender, age, education, marital and regional distributions, but they were from nearby unaffected areas. In the present study we examined only those who have participate the first study (victims and controls). Eligible participants were residents who lived in the prefecture of Ilia, had taken part in the previous study (6 months after the wildfires) and were aged from 18 to 65 years old at that time.

\subsection{Measurements}

1) Demographic characteristics (age, gender, educational background, marital status, occupation).

2) Number and type of damages (financial or personal) as a result of the fire including: a) damage to property (Yes vs No), b) complete damage to property (Yes vs No), c) personal injury or injury of a close family member (Yes vs No), and d) deaths of close family members (Yes vs No). The responses to questions a) and b) were mutually exclusive (thus, if a person suffered complete damage to property, he/she was not included in the group of people that had suffered partial damage). If more than one loss had occurred, all of them counted (number of losses).

3) WHOQOL-BREF (Greek version). The WHOQOLBREF is a self-report 26-item Quality of Life (QoL) inventory developed by the World Health Organization. It has shown relevance in cross-cultural research in a WHOQOL pilot field trial of 15 centers in developed and developing countries using 12 languages [19] and has shown good to excellent reliability and validity [20]. It has four domains: a) physical health, b) psychological health, c) social relationships and d) environment. Also, two more items are included referring to overall QoL/ health. The Greek version is a 30 -item form with 4 new national items referring to: 1) nutrition, 2) satisfaction with work, 3) home life and 4) social life [21,22]. For reasons of comparability with other studies, we did not analyse those extra 4 items in the WHOQOL. After transforming the reversed items, all questions in the WHOQOL-BREF are scored in such a way that the higher scores indicate a better QoL.

4) Psychological distress at first assessments: The Greek version of Symptom Checklist 90-Revised (SCL90-R) [23] was used to identify potential psychiatric caseness. The Greek version of SCL-90-R has shown a sensitivity of 0.98 and a specificity of 0.74 in indicating active psychiatric patients [24]. The SCL-90-R has 90 items, which measure the degree of distress experienced by the individual during the last 7 days, using a 5-point scale (0 to 4$)$ that ranges from "not at all" to "extremely". The SCL-90-R can be scored for nine symptom dimensions (Somatization, Obsessive-Compulsive, Interpersonal Sensitivity, Depression, Anxiety, Hostility, Phobic Anxiety, Paranoid Ideation, and Psychoticism). In addition to the nine scales, there are three global indices that are computed: the Global Severity Index (GSI), the Positive Symptom Total (PST) and the Positive Symptom Distress Index (PSDI). According to SCL-90-R [23], caseness is identified when a respondent has a GSI score greater or equal to a $T$ score of 63 , or if any of two dimensions scores are greater than or equal to a $T$ score of 63.

\subsection{Procedure}

Data were collected during face-to-face interviews. The interviewers had previously been trained in the use of scales under the supervision of one of authors. The first wave of assessments started six months after the outbreak of the wildfires (March, 2008) and the second (present) three years after the disaster (August, 2010). We assessed the quality of life only in one prefecture (Ilia) for two reasons. First, it was the area with the most devastating damages caused by the disaster (and also the area which received the bulk of support) and the second 
reason was that because of financial restrictions it was not possible to survey the entire initial sample.

\subsection{Ethics}

The study was approved by the Ministry of Health and informed consent was obtained from each participant. The purpose of this study was explained to the participants. All information was presented verbally and in writing. No inducement was provided.

\subsection{Statistical Analysis}

The data were analysed with PASW (SPSS, ver. 18), using appropriate bivariate statistics for comparison of the quality of life between cases (victims of the wildfire) and controls (those not affected by the disaster). One way ANOVA was used to compare the quality of life in variables with more than two levels (e.g. education, marital status) with Bonferonni corrections for the multiple testing. A multivariate model was constructed to investigate and estimate the effects of demographic characteristics, losses, and previous psychological problems (as determined via the use of SCL-90-R) in the four domains of WHOQOL-BREF.

\section{RESULTS}

\subsection{Demographics}

The initial sample was 400 participants (200 affected by the disaster and 200 controls). It was not possible to contact 33 of them and three more participants were excluded from the rest (367) as they did not answer the minimum number of questions that the WHOQOLBREF requires. Thus, the total analysed sample was 364 participants (184 victims and 180 controls). The mean age of the sample was 43.1 (SD: 13.4) years old and ages ranged from 21 to 68 years old. The two groups (victims/ controls) were not different in age (t-test, $\mathrm{t}=0.57$, df: $362, \mathrm{p}=0.57)$. Similarly, the two groups were closely matched in terms of gender, education, occupation and regional characteristics. The demographic characteristics and the comparison of the two groups ( $\chi^{2}$ tests) are given in Table 1.

\subsection{Quality of Life (WHOQOL-BREF)}

Table 2 shows the results of the WHOQOL-BREF scale and the comparisons between the groups. Victims had a lower quality of life in the three domains (physical, psychological health and environment) compared to controls, but no differences were found in social relationships. The male gender had a better quality of life compared to females in the domains of psychological health, social relationships and environment. Those with lower education and elementary occupation had worse quality of life compared to the other groups. Similarly, age (not shown in Table 2) had a linear relationship with the quality of life in the four domains. Younger age was associated with a better quality of life in both victims and controls. Furthermore, those with damages to their properties had a worse quality of life compared to those without any damages in the domains of psychological health, social relationships and environment, while those with complete loss of property had a lower quality of life only in

Table 1. Demographic characteristics of sample.

\begin{tabular}{|c|c|c|c|c|}
\hline & & Cases $N=184(\%)$ & Controls N = $180(\%)$ & Pearson $X^{2}$ \\
\hline \multirow{3}{*}{ Gender } & Male & $95(51.6)$ & $92(51.1)$ & \multirow{3}{*}{$\mathrm{x}^{2}=0.10$, df $1, \mathrm{p}=0.9(\mathrm{NS})$} \\
\hline & & & & \\
\hline & Female & $89(48.8)$ & 88 (48.9) & \\
\hline \multirow{2}{*}{ Education } & Primary school & $49(26.6)$ & $53(29.4)$ & \multirow{2}{*}{$x^{2}=1.1$, df $2, p=0.6(N S)$} \\
\hline & College/university & $9(4.9)$ & $12(6.7)$ & \\
\hline \multirow{5}{*}{ Marital status } & Married & $122(66.3)$ & $125(69.4)$ & \multirow{5}{*}{$\mathrm{x}^{2}=3.1, \mathrm{df} 3, \mathrm{p}=0.36(\mathrm{NS})$} \\
\hline & Single & $54(29.3)$ & $51(28.3)$ & \\
\hline & & & & \\
\hline & Divorced & $1(0.5)$ & $2(1.1)$ & \\
\hline & Widowed & $7(3.8)$ & $2(1.1)$ & \\
\hline \multirow{3}{*}{ Occupation } & Professional & $1(0.6)$ & $2(1.1)$ & \multirow{3}{*}{$x^{2}=0.45$, df $2, p=0.79(N S)$} \\
\hline & Sales and customer service & $67(37)$ & $63(35.2)$ & \\
\hline & Elementary & $113(62.4)$ & $114(63.7)$ & \\
\hline
\end{tabular}


Table 2. Differences of groups in the four different domains of WHOQOL-BREF.

\begin{tabular}{|c|c|c|c|c|c|c|c|c|c|c|}
\hline & & \multirow{2}{*}{$\mathrm{n}$} & \multicolumn{2}{|c|}{ Physical health } & \multicolumn{2}{|c|}{ Psychological health } & \multicolumn{2}{|c|}{ Social relationships } & \multicolumn{2}{|c|}{ Environment } \\
\hline & & & Mean & Levels & Mean & Levels & Mean & & Mean & \\
\hline \multirow{2}{*}{ Participants } & Victims & 184 & $16.20 * *$ & & $15.38 * *$ & & 16.00 & & $12.58^{* *}$ & \\
\hline & Controls & 180 & 16.82 & & 15.97 & & 16.00 & & 14.07 & \\
\hline \multirow{2}{*}{ Gender } & Male & 187 & 16.67 & & $16.05^{* *}$ & & $16.56 * *$ & & $13.61^{* *}$ & \\
\hline & Female & 177 & 16.32 & & 15.27 & & 15.41 & & 13.00 & \\
\hline \multirow{3}{*}{ Education } & Primary school & 102 & $15.11 * *$ & $\mathrm{~S}, \mathrm{C}$ & $14.42 * *$ & $\mathrm{~S}, \mathrm{C}$ & $14.75^{* *}$ & $\mathrm{~S}, \mathrm{C}$ & $12.43 * *$ & $\mathrm{~S}, \mathrm{C}$ \\
\hline & Secondary school & 241 & 16.99 & & 16.09 & & 16.48 & & 13.57 & \\
\hline & College/university & 21 & 17.69 & & 16.89 & & 16.60 & & 14.64 & \\
\hline \multirow{4}{*}{ Marital status } & Married & 247 & 16.12 & & $15.29 * *$ & W & 15.40 & & 13.03 & \\
\hline & Single & 105 & $17.66^{* *}$ & $\mathrm{M}, \mathrm{D}, \mathrm{W}$ & $16.86^{* *}$ & $\mathrm{M}, \mathrm{D}, \mathrm{W}$ & $17.52 * *$ & $\mathrm{M}, \mathrm{W}$ & $14.16^{* *}$ & M, W \\
\hline & Divorced & 3 & $13.14 * *$ & $\mathrm{~S}$ & $12.89 * *$ & $\mathrm{~S}$ & 16.22 & & 12.71 & \\
\hline & Widowed & 9 & 14.79 & & $13.11 * *$ & $\mathrm{M}, \mathrm{S}$ & 14.81 & & 11.54 & \\
\hline \multirow{3}{*}{ Occupation } & Professional & 79 & 16.71 & & 15.90 & & 16.23 & & 13.63 & \\
\hline & $\begin{array}{l}\text { Sales and customer } \\
\text { service }\end{array}$ & 66 & 17.42 & & 16.55 & E & 16.76 & & 13.84 & \\
\hline & Elementary & 219 & $16.15^{* *}$ & $\mathrm{P}, \mathrm{S}$ & $15.32 * *$ & $\mathrm{P}, \mathrm{S}$ & $15.69 * *$ & $\mathrm{P}, \mathrm{S}$ & $13.04 * *$ & $\mathrm{P}, \mathrm{S}$ \\
\hline \multirow{2}{*}{ Damages } & No & 246 & $16.73 * *$ & & $15.83^{*}$ & & 15.98 & & $13.66^{* *}$ & \\
\hline & Yes & 118 & 16.03 & & 15.33 & & 16.04 & & 12.58 & \\
\hline \multirow{2}{*}{$\begin{array}{l}\text { Complete loss } \\
\text { of property }\end{array}$} & No & 320 & 16.56 & & 15.73 & & 16.07 & & $13.46^{* *}$ & \\
\hline & Yes & 44 & 16.10 & & 15.23 & & 15.53 & & 12.26 & \\
\hline \multirow{2}{*}{ Injuries } & No & 356 & 16.50 & & 15.67 & & 16.00 & & 13.31 & \\
\hline & Yes & 8 & 16.71 & & 15.75 & & 15.92 & & 13.58 & \\
\hline \multirow{2}{*}{ Deaths } & No & 345 & 16.48 & & 15.66 & & 16.01 & & 13.32 & \\
\hline & Yes & 19 & 16.90 & & 15.93 & & 15.93 & & 13.17 & \\
\hline \multirow{4}{*}{$\mathrm{N}$ of losses } & 0 & 199 & $16.88^{* *}$ & One & $16.02 * *$ & One & 16.10 & & $13.98 * *$ & one \\
\hline & 1 & 142 & 15.90 & & 15.11 & & 15.87 & & 12.38 & \\
\hline & 2 & 22 & 16.78 & & 16.00 & & 15.73 & & 13.24 & \\
\hline & 3 & 1 & & \multicolumn{7}{|c|}{ Only one case (not computed) } \\
\hline
\end{tabular}

$*=\mathrm{p}<0.05, * *=\mathrm{p}<0.01$.

the environment domain.

\subsection{Predictive Factors for Quality of Life}

In addition to bivariate statistics, we further analyzed the data to adjust for confounding factors. For this reason, a multivariate model was conducted. The dependent variables used were the four domains of the WHOQOLBREF and the independent variables were age, education (three categories), occupation (three categories), marital status (four categories) the variable of participants (case/ control), the binary variables regarding losses (damages to property, complete loss of property, injuries, deaths) and in addition we included a variable of psychopathology (SCL-90-R), caseness or not, from the data which we had collected two and half years earlier. Variables which did not have any significant effect on any of the domains of WHOQOL-BREF were excluded one by one till a final parsimonious model was found. Table 3 shows only the significant main effects and the parameter esti- 
Table 3. Multivariate model for predictive factors for QoL.

\begin{tabular}{|c|c|c|c|c|c|c|c|c|}
\hline \multirow{2}{*}{$\begin{array}{c}\text { Dependent } \\
\text { Variable }\end{array}$} & \multirow{2}{*}{ Parameter } & \multirow{2}{*}{$\mathrm{B}$} & \multirow{2}{*}{ Std. Error } & \multirow{2}{*}{$\mathrm{t}$} & \multirow{2}{*}{ Sig. } & \multicolumn{2}{|c|}{$95 \%$ Confidence Interval } & \multirow{2}{*}{$\begin{array}{l}\text { Observed } \\
\text { Power }^{\mathrm{a}}\end{array}$} \\
\hline & & & & & & Lower & Upper & \\
\hline \multirow{6}{*}{ Physical health } & Intercept & 22.918 & 1.435 & 15.973 & 0.000 & 20.089 & 25.748 & 1.000 \\
\hline & Married & 0.386 & 0.694 & 0.556 & 0.579 & -0.982 & 1.754 & 0.086 \\
\hline & Single & 0.175 & 0.772 & 0.227 & 0.820 & -1.347 & 1.698 & 0.056 \\
\hline & Divorced & -6.195 & 1.975 & -3.136 & 0.002 & -10.091 & -2.300 & 0.877 \\
\hline & Widowed & $0^{\mathrm{b}}$ & - & - & - & - & - & - \\
\hline & Age & -0.109 & 0.014 & -8.065 & 0.000 & -0.136 & -0.083 & 1.000 \\
\hline \multirow{4}{*}{$\begin{array}{l}\text { Psychological } \\
\text { health }\end{array}$} & Intercept & 20.723 & 1.372 & 15.099 & 0.000 & 18.017 & 23.430 & 1.000 \\
\hline & Male & 0.767 & 0.249 & 3.082 & 0.002 & 0.276 & 1.258 & 0.866 \\
\hline & Female & $0^{\mathrm{b}}$ & - & - & - & - & - & - \\
\hline & Age & -0.101 & 0.013 & -7.820 & 0.000 & -0.127 & -0.076 & 1.000 \\
\hline \multirow{4}{*}{$\begin{array}{c}\text { Social } \\
\text { relationships }\end{array}$} & Intercept & 17.053 & 1.636 & 10.427 & 0.000 & 13.828 & 20.278 & 1.000 \\
\hline & Male & 1.159 & 0.297 & 3.907 & 0.000 & 0.574 & 1.743 & 0.973 \\
\hline & Female & $0^{\mathrm{b}}$ & - & - & - & - & - & - \\
\hline & Age & -0.048 & 0.015 & -3.120 & 0.002 & -0.079 & -0.018 & 0.874 \\
\hline \multirow{9}{*}{ Environment } & Intercept & 18.559 & 1.511 & 12.280 & 0.000 & 15.579 & 21.539 & 1.000 \\
\hline & Male & 0.639 & 0.274 & 2.333 & 0.021 & 0.099 & 1.180 & 0.641 \\
\hline & Female & $0^{\mathrm{b}}$ & - & - & - & - & - & - \\
\hline & Age & -0.062 & 0.014 & -4.364 & 0.000 & -0.090 & -0.034 & 0.991 \\
\hline & Victims & -1.679 & 0.385 & -4.359 & 0.000 & -2.439 & -0.920 & 0.991 \\
\hline & Controls & $0^{\mathrm{b}}$ & - & - & - & - & - & - \\
\hline & $\begin{array}{l}\text { Primary } \\
\text { School }\end{array}$ & -1.397 & 0.672 & -2.080 & 0.039 & -2.721 & -0.073 & 0.544 \\
\hline & $\begin{array}{l}\text { Secondary } \\
\text { School }\end{array}$ & -1.261 & 0.611 & -2.065 & 0.040 & -2.465 & -0.057 & 0.538 \\
\hline & $\begin{array}{l}\text { College/ } \\
\text { University }\end{array}$ & $0^{\mathrm{b}}$ & - & - & - & - & - & - \\
\hline
\end{tabular}

${ }^{\mathrm{a}}$ Computed using alpha $=0.05$; $^{\mathrm{b}}$ This parameter is set to zero because it is redundant. The signs in the estimates column indicate the direction of the relationship, i.e., the (-) means that this variable contributes negatively (e.g., older age-increased years-, lower score in quality of life inventory).

mates of the final model.

As it can be seen in Table 3, the victims of the disaster had a lower quality of life only in one domain; which was the environment. In addition, both the losses caused by the catastrophic event (damages, injuries, deaths) and the previous psychopathology, did not have any significant effect on the quality of life 3 years later. On the opposite, age was a significant factor for all the domains of quality of life. Older people had a lower quality of life. From the other demographic variables it can be seen that the male gender had a better quality of life in the domains of psychological health, social relationships, and environment compared to the female, and higher educa- tion had a protective effect on the domain of the environmental quality of life, whereas those divorced had a lower quality of life in terms of physical health.

\section{DISCUSSION}

The results show that those exposed to the wildfire disaster had a poorer quality of life in the three domains of physical health, psychological health, and environment compared to controls. However, those differences disappeared when the data were controlled for confounding variables and the only difference between victims and controls was in the environment domain. The environ- 
ment domain of WHOQOL-BREF contains items which measure living conditions, availability and access to services (health, transport), availability of information, financial matters, safety and leisure. In all of those questions victims scored lower. Similar results have been reported by other studies which evaluate the quality of life in populations affected by a disaster. For instance, a study [25] reported a poor quality of life in the victims of Chi-Chi earthquake 3 years later, and another [11] with a longitudinal design found that the victims of the earthquake had an impaired quality of life in the physical, psychological and environmental domains 3 months after the disaster, and in the psychological and environmental domains 9 months later. In other types of disasters, such as floods, or hurricanes [13,26,27] also a poorer QoL in the three domains (physical, psychological and environmental) in victims compared to controls was reported. However, a number of studies (often with a very long time of follow-up) did not report any differences [28,29]. In our study we did not find differences in psychological or physical well-being after controlling for other factors. Although in our first study we found that the victims of the wildfires had increased psychological problems compared to controls [18], it seems that 3 years later most of the psychological distress has been reduced. However, the effects of the disaster were present even 3 years later and the affected population still had difficulties in gaining access to essential service. In addition, given that the area is rural and the main occupations are agricultural jobs, the financial difficulties may persist for a longer time period, as the land has been destroyed by the fires. Taking into account the previously reported studies, it is possible that while psychological and physical health may have improved over time the environmental quality of life will take longer. Although compensation has been given to victims after the wildfires, the reduction in the quality of life cannot be measured only in monetary terms. The secondary effects of a disaster on a population result not only in the loss of income caused by the partial, temporary or total interruption of their activities but also in the decline of the living conditions and the difficulties in gaining access to their sources of supply and services.

Furthermore, we found that older age (for all the four dimensions) and the female gender for the psychological, social and environment domains were other risk factors for poor quality of life, and also that divorced people had a higher risk of developing poor physical health, while higher education was a protective factor for the environmental domain of quality of life. Similar results regarding demographic variables have been reported in a number of studies on victims of disasters e.g. [11-13,30], and also in other causes of trauma (e.g. in post-conflict displaced populations, [31]).

A limitation of our study is that we did not have any data regarding the quality of life before the disaster to make comparisons, but also we had not collected data on the quality of life in the first wave of assessments. Although it seems that there is a decrease of psychological distress during the 3 post disaster years, we do not know if a persistent low quality of life in the environmental domain can cause lower quality of life in other domains in the future. This is a hypothesis which merits further investigation.

\section{REFERENCES}

[1] Norris, F.H., Friedman, M.J., Watson, P.J., Byrne, C.M., Diaz, E. and Kaniasty, K. (2002) 60,000 disaster victims speak: Part I. An empirical review of the empirical literature, 1981-2001. Psychiatry, 65, 207-239. doi:10.1521/psyc.65.3.207.20173

[2] Ursano, J., Fullerton, C. and Benedek, D. (2009) What is psychopathology after disasters? Considerations about the nature of the psychological and behavioral consequences of disasters. In: Neria, Y., Galea, S. and Norris, F.H., Eds., Mental Health and Disasters, Cambridge University Press, Cambridge, New York, 131-144.

[3] Lin, M.-R., Huang, W., Huang, C., Hwang, H.-F., Tsai, L.-W. and Chiu, Y.-N. (2002) The impact of the Chi-Chi earthquake on quality of life among elderly survivors in Taiwan: A before and after study. Quality of Life Research, 11, 379-388. doi:10.1023/A:1015543113448

[4] Yzermans, C.J., Donker, G.A., Kerssens, J.J., Dirkzwager, A.J.E., Soeteman, R.J.H. and Ten Veen, P.M.H. (2005) Health problems of victims before and after disaster: A longitudinal study in general practice. International Journal of Epidemiology, 34, 820-826. doi:10.1093/ije/dyi096

[5] World Health Organization (1995) Resources for new WHOQOL centers. WHO (MNH/PSE/95.2), Geneva.

[6] Skevington, S.M., Lotfy, M., O'Connell, K.A. (2004) The World Health Organization's WHOQOL-BREF quality of life assessment: Psychometric properties and results of the international field trial. A Report from the WHOQOL Group. Quality of Life Research, 13, 299-310. doi:10.1023/B:QURE.0000018486.91360.00

[7] Mohan, A., Mohan, C., Bhutani, M., Pathak, A.K., Pal, H., Das, C. and Guleria, R. (2006) Quality of life in newly diagnosed patients with lung cancer in a developing country: Is it important? European Journal of Cancer Care, 15, 293-298. doi:10.1111/j.1365-2354.2006.00654.x

[8] Sung, S.C. and Yeh, M.Y. (2007) Factors related to quality of life in depressive outpatients in Taiwan. Psychiatry Clinical Neuroscience, 61, 610-615. doi:10.1111/j.1440-1819.2007.01726.X

[9] Tsai, Y.C., Hung, C.C., Hwang, S.J., Wang, S.L., Hsiao, S.M., Lin, M.Y. and Chen, H.C. (2010) Quality of life predicts risks of end-stage renal disease and mortality in patients with chronic kidney disease. Nephrology Dialysis Transplant, 25, 1621-1626. doi:10.1093/ndt/gfp671

[10] Vikas, A., Avasthi, A. and Sharan, P. (2011) Psychoso- 
cial impact of obsessive-compulsive disorder on patients and their caregivers: A comparative study with depressive disorder. International Journal of Social Psychiatry, 57, 45-56. doi:10.1177/0020764010347333

[11] Wang, X., Gao, L., Zhang, H., Zhao, C., Shen, Y. and Shinfuku, N. (2000) Post-earthquake quality of life and psychological well-being: Longitudinal evaluation in a rural community sample in northern China. Psychiatry Clinical Neuroscience, 54, 427-433. doi:10.1046/j.1440-1819.2000.00732.x

[12] Choul, F.H., Chou, P., Lin, C., Su, T.T., Ou-Yang, W.C., Chien, et al. (2004) The relationship between quality of life and psychiatric impairment for a Taiwanese community post-earthquake. Quality of Life Research, 13, 10891097. doi:10.1023/B:QURE.0000031337.73269.64

[13] Tan, H.Z., Luo, Y.J., Wen, S.W., Liu, A.Z., Li, S.Q., Yang, T.B. and Sun, Z.Q. (2004) The effect of a disastrous flood on the quality of life in Dongting lake area in China. Asia-Pacific Journal of Public Health, 16, 126132. doi:10.1177/101053950401600209

[14] Tang, C.S. (2007) Trajectory of traumatic stress symptoms in the aftermath of extreme natural disaster: A study of adult Thai survivors of the 2004 Southeast Asian earthquake and tsunami. The Journal of Nervous and Mental Disease, 195, 54-59. doi:10.1097/01.nmd.0000242971.84798.bc

[15] Chen, Y.S., Chen, M.C., Chou, F.H., Sun, F.C., Chen, P.C., Tsai, K.Y. and Chao, S.S. (2007) The relationship between quality of life and posttraumatic stress disorder or major depression for firefighters in Kaohsiung, Taiwan. Quality of Life Research, 16, 1289-1297. doi:10.1007/s11136-007-9248-7

[16] Norris, F.H., Phifer J.F. and Kaniasty K. (2006) Individual and community reactions to the Kentucky floods: Findings from a longitudinal study of older adults. In: Ursano, R.J., Mccaughey, B.G. and Fullerton C.S., Eds., Individual and Community Responses to Trauma and Disaster the Structure of Human Chaos, Cambridge University Press, New York, 378-402.

[17] EM-DAT (2008) The OFDA/CRED international disaster database prevention web.

http://www.preventionweb.net/english/countries/statistics index.php?cid $=68$

[18] Papanikolaou, V., Adamis, D., Mellon, R.C. and Prodromitis, G. (2011) Psychological distress following wildfires disaster in a rural part of Greece: A case-control population-based study. International Journal of Emergency Mental Health, 13, 11-26.

[19] Saxena, S., Carlson, D. and Billington, R. (2001) The WHO quality of life assessment instrument (WHOQOLBrief): The importance of its items for cross-cultural research. Quality of Life Research, 10, 711-721. doi:10.1023/A:1013867826835

[20] Skevington, S.M., Lotfy, M. and O'Connell, K.A. (2004) The World Health Organization's WHOQOL-BREF quality of life assessment: Psychometric properties and results of the international field trial. A report from the WHOQOL group. Quality of Life Research, 13, 299-310.

\section{doi:10.1023/B:QURE.0000018486.91360.00}

[21] Ginieri-Coccossis, M., Triantafillou, E., Antonopoulou, V., Tomaras, V. and Christodoulou, G.N. (2003) Quality of life handbook in reference to WHOQOL-100. Medical Publications VITA, Athens (in Greek).

[22] Ginieri-Coccossis, M., Triantafillou, E., Tomaras, V., Mavreas V. and Soldatos C. (2006) Psychometric properties of the World Health Organization quality of life instrument-Greek version (WHOQOLBREF). 9th PanHellenic Psychiatric Congress, Athens, 4-8 May 2006.

[23] Derogatis, L.R. (1992) SCL-90-R: Administration, scoring \& procedures manual-II, for the R(revised) version and other instruments of the psychopathology rating scale series. 2nd Edition, Clinical Psychometric Research, Towson.

[24] Donias, S., Karastergiou, A. and Manos, N. (1991) Standardization of the symptom checklist 90 rating scale in a Greek population. Psychiatriki, 2, 42-48.

[25] Wu, H.C., Chou, P., Chou, F.H., Su, C.Y., Tsai, K.Y., Ou-Yang, W.C., et al. (2006) Survey of quality of life and related risk factors for a Taiwanese village population 3 years post-earthquake. Australia and New Zealand Journal of Psychiatry, 40, 355-361. doi:10.1080/j.1440-1614.2006.01802.x

[26] LaJoie, A.S., Sprang, G. and McKinney, W.P. (2010) Long-term effects of Hurricane Katrina on the psychological well-being of evacuees. Disasters, 34, 1031-1044. doi:10.1111/j.1467-7717.2010.01181.x

[27] Ceyhan, E. and Ceyhan, A.A. (2007) Earthquake survivors' quality of life and academic achievement six years after the earthquakes in Marmara, Turkey. Disasters, 31, 516-529. doi:10.1111/j.1467-7717.2007.01023.x

[28] Priebe, S., Marchi, F., Bini, L., Flego, M., Costa, A. and Galeazzi, G. (2011) Mental disorders, psychological symptoms and quality of life 8 years after an earthquake: Findings from a community sample in Italy. Social Psychiatry and Psychiatric Epidemiology, 46, 615-621. doi:10.1007/s00127-010-0227-X

[29] Carrasco, J.M., Perez-Gomez, B., Garcia-Mendizabal, M.J., Lope, V., Aragones, N., Forjaz, M.J., Guallar-Castillon, P., Lopez-Abente, G., Rodriguez-Artalejo, F. and Pollan, M. (2007) Health-related quality of life and mental health in the medium-term aftermath of the Prestige oil spill in Galiza (Spain): A cross-sectional study. BMC Public Health, 7, 245. doi:10.1186/1471-2458-7-245

[30] Suzuki, Y., Tsutsumi, A., Fukasawa, M., Honma, H., Someya, T. and Kim, Y. (2011) Prevalence of mental disorders and suicidal thoughts among community-dwelling elderly adults 3 years after the niigata-chuetsu earthquake. Journal of Epidemiology, 21, 144-150. doi:10.2188/jea.JE20100093

[31] Araya, M., Chotai, J., Komproe, I.H. and De Jong, J.T. (2007) Effect of trauma on quality of life as mediated by mental distress and moderated by coping and social support among post conflict displaced Ethiopians. Quality of Life Research, 16, 915-927. doi:10.1007/s11136-007-9201-9 